\title{
A pessoa humana como centro e fim do direito: a positivação da dignidade da pessoa humana
}

\author{
Agenor Casaril*
}

\section{INTRODUÇÃO}

No pensamento humanístico contemporâneo, os temas da pessoa humana e a dignidade e direitos a ela inerentes constituem questões centrais, assim da ciência como da filosofia do direito. Têm eles se constituído, nas últimas décadas, em valores políticos superiores que devem-se consagrar, garantir e proteger. ${ }^{1}$

Até meados do século XX, a dignidade da pessoa humana não havia alcançado o pleno reconhecimento no mundo jurídico. Hodiernamente, os ordenamentos jurídicos tendem ao reconhecimento da pessoa humana como o centro e o fim do Direito; ${ }^{2}$ positivando a dignidade da pessoa humana como valor básico e princípio fundante do Estado Democrático de Direito.

Com efeito, pondera J. Gomes Canotilho ${ }^{3}$ que o conceito de dignidade da pessoa humana é concebido como referência constitucional unificadora de todos os direitos fundamentais. Porém, para além desse horizonte, outras conseqüências decorrem da adoção do conceito, pois, elevado a princípio, obriga a uma densificação valorativa que leve em consideração o seu abrangente sentido normativo-constitucional para

* Professor na FMP, FESDEP e Faculdade de Direito São Judas Tadeu.

1 PEREZ, Jesus Gonzalez. La dignidad de la persona. Madrid: Civitas, 1986, p.19.

2 NOBRE JÚNIOR, Edilson Pereira. O direito brasileiro e o princípio da dignidade da pessoa humana. Revista de Direito Administrativo.Rio de Janeiro, v. 219, p.237-251, janeiro/março de 2000, p.238.

3 CANOTILHO, José Joaquim Gomes et MOREIRA, Vital. Constituição da República Portuguesa Anotada. 2.ed. Coimbra: Coimbra ed., 1984, v.1, p.70. 
além de mera idéia apriorística do homem. Logo, infere o nominado autor, não é possível reduzir-se o sentido da dignidade humana à defesa dos direitos pessoais tradicionais, ou invocá-la para construir 'teoria do núcleo da personalidade' individual, ignorando-a no espaço dos direitos econômicos, sociais e culturais." ${ }^{4}$

\section{FUNDAMENTO PRIMORDIAL DO DIREITO}

A pessoa humana é o fundamento primeiro do direito. Com efeito, o homem é o ser que, dentro do tempo e do espaço, se apresenta e deve ser considerado como 'centro e fim' de tudo o que existe, pois ele é pessoa, isto é, o ser em consciência e em liberdade. Esta sua identidade o torna o valor absoluto - o único valor absoluto - a que tudo se refere. ${ }^{5} \mathrm{O}$ absolutismo do homem, dentro da realidade do mundo, afirma-lhe o primado ontológico e finalístico: ele é o ser supremo, não podendo, por isso, ser instrumentalizado.

Este primado do homem não pode não ser reconhecido, acolhido, respeitado, promovido e tutelado. ${ }^{6}$ Assim, sendo a pessoa humana o fundamento primeiro do direito, é ela, em decorrência, a fonte originária dos conteúdos primordiais deste. ${ }^{7}$ Segue-se que a pessoa humana, impondo-se como fundamento primeiro do direito e fonte originária de seus conteúdos primordiais, constitui a justificação última da obrigatoriedade deste. ${ }^{8}$

O direito tem um finalismo próprio que lhe legitima a presença na vida humana, consistente na busca do bem comum no qual se complementa o crescimento integral do homem. Tal finalismo jurídico se inscreve, obviamente, no finalismo da pessoa humana, porquanto esta é o fim último de tudo quanto existe no tempo e no espaço. ${ }^{9}$

Tanto na ordem político-jurídica internacional como nos ordenamentos jurídicos internos dos estados modernos, têm proliferado os documentos declaratórios de direitos em que os direitos fundamentais e a dignidade da pessoa humana aparecem como núcleo central de tais declarações. O que não tem nelas aparecido com clareza é uma convincente fundamentação de tais direitos, isto é, o fundamento e razão

4 CANOTILHO, José Joaquim Gomes et MOREIRA, Vital. Constituição da República Portuguesa Anotada. 2.ed. Coimbra: Coimbra ed., 1984, v.1, p.70.

5 MARTINI, Agostino. Il diritto nella realtà umana. Il diritto nel mistero della Chiesa Pontificium institutum utriusque juris - Pontificia Università Lateranense: Roma, 1986, p.6.

6 Idem, p.7.

7 Ibidem p. 8.

8 Ibidem, p. 9.

9 MARTINI, Agostino. Op. cit., p.10. 
de ser deles, sua origem e razões transcendentes, como se existissem simplesmente porque favorecidos por maioria de votos nos organismos internacionais e nos parlamentos, na ponderação de Perez. ${ }^{10}$

Esta carência de uma adequada fundamentação conduz à conclusão de que a dignidade humana é intangível só porque foi assim decidido. Isto explica que, em nome da dignidade da pessoa humana, se chegue a soluções radicalmente opostas, relativamente a temas fundamentais de nosso tempo. Tais são a admissibilidade de certas formas de procriação humana, a manipulação genética, a disponibilidade de órgãos humanos, os experimentos médicos com pessoas, o aborto e a eutanásia. ${ }^{11}$

Em verdade, ao solucionar, juridicamente, questões relativas à dignidade humana, a diferente concepção teórica que se lhe antepuser resultará em soluções diferentes e, até, diametralmente opostas. Disto decorre a necessidade de adoção de um fundamento último que radique na essência da dignidade humana, gerando segurança jurídica aos jurisdicionados. Para tal, mais adequada a concepção do personalismo cristão, que transcende a visão, limitada e limitante, do puro racionalismo cartesiano e mesmo kantiano. Com efeito, a dignidade da pessoa humana fundamenta-se não só na autoconsciência ou racionalidade, mas, simultaneamente, na liberdade, na comunicação e na auto-transcendência do homem.

Em realidade, os países cujos povos inserem em seu ideal político a concretização de um regime democrático, constituído em Estado Democrático de Direito, dão realce à dignidade da pessoa humana e buscam sua proteção em seus ordenamentos jurídicos. Com efeito, via ordem constitucional, buscam prevenir que, em nome de ideologias, cometam-se abusos brutais contra a dignidade humana, como os ocorridos em pleno século XX, sob o influxo do totalitarismo, independente dos matizes deste.

Com efeito, plenamente pertinente a ponderação oferecida por Lafer, ao estabelecer que a posição expressamente adotada pelo totalitarismo, no sentido "de que os seres humanos são supérfluos e descartáveis, representa uma contestação frontal à idéia do valor da pessoa enquanto "valor-fonte" de todos os valores políticos, sociais e econômicos" e, em decorrência, ao fundamento último da legitimidade da ordem jurídica, como formulado pela tradição, assim no âmbito do paradigma do Direito Natural como no da Filosofia do Direito. ${ }^{12}$

10 PEREZ, Jesus Gonzalez. Op. cit., p.19.

11 PEREZ, Jesus Gonzalez. Op. cit., p.19-20.

12 LAFER, Celso. A reconstrução dos direitos humanos. São Paulo: Companhia das Letras, 1988, p.19. 
Com razão, ante o imperativo de respeito irrestrito à dignidade da pessoa humana, ponderou-se que "Hitler impôs aos homens um novo imperativo categórico: organizar o seu agir e pensar de modo que Auschwitz não se repita, que nada de semelhante aconteça." ${ }^{\prime \prime}$

\section{CONSTITUIÇÕES QUE INSPIRARAM A BRASILEIRA NA POSITIVAÇÃO DO PRINCÍPIO DA DIGNIDADE DA PESSOA HUMANA}

Alguns ordenamentos constitucionais inspiraram a Constituição brasileira vigente. Tais são o alemão, o espanhol, o italiano e o português, entre outros. A estes far-se-á referência e breve análise das disposições normativas relativas ao princípio.

\subsection{A Lei Fundamental da Alemanha}

Com efeito, no âmbito histórico e geográfico, admitidas algumas exceções, ${ }^{14}$ a Lei Fundamental da República Federal da Alemanha, promulgada em 23 de maio de 1949, é dada como a que, pioneiramente, consagrou a dignidade da pessoa humana em seu texto, de modo expresso e solene, erigindo-a em direito fundamental, estabelecido no seu art. $1^{\circ}, \mathrm{n}^{\mathrm{o}} 1$, nos seguintes termos: A dignidade humana é inviolável. Respeitá-la e protegê-la é obrigação de todos os Poderes estatais.

Em complemento, dispõe o $\mathrm{n}^{\mathrm{o}} 2$ : $O$ povo alemão se identifica, portanto, com os invioláveis e inalienáveis direitos do homem como fundamento de toda a comunidade humana, da paz e da justiça no mundo.

Afirma José Afonso da Silva que a positivação constitucional do princípio da dignidade da pessoa humana fundamenta-se no fato de o Estado nazista ter vulnerado gravemente tal dignidade mediante a prática de horrorosos crimes políticos sob a invo-

13 ADORNO, Theodor W. Dialética Negativa, p. 330, apud GALEAZZI, Umberto. Por uma libertação da prisão da imanência. In: Deus na filosofia do Século XX. São Paulo: Loyola, 1998, p.359.

14 Ingo Wolfgang Sarlet, em nota à p. 63 de sua Dignidade da pessoa humana e direitos fundamentais..., refere que a Constituição Alemã, conhecida como de Weimar (1919), já havia previsto, em seu art. 151, I, o princípio da dignidade da pessoa humana, ao estabelecer que o objetivo maior da ordem econômica é o de garantir uma existência digna. De igual modo, salienta, a Constituição Portuguesa de 1933 (art. 6, nº 3 ) e a da Irlanda, de 1937, em seu Preâmbulo, faziam referência expressa à dignidade da pessoa humana. (SARLET, Ingo Wolfgang. Dignidade da pessoa humana e direitos fundamentais na Constituição Federal de 1988. Porto Alegre: Livraria do Advogado, 2001.) 
cação de razões de Estado e outras." 15 O que é confirmado por Hesse. ${ }^{16}$

Quanto ao conteúdo de tal princípio da Lei Fundamental tedesca, não menos incisivo é Verdú ao asseverar que foi proclamada a dignidade humana como princípio lógico, ontológico e deontológico de todos os direitos, tendo-se invocado a Deus no preâmbulo da 'Grundgesetz' e na dos 'Laender'. Foi estabelecido o Estado de Direito como Estado social de Direito e se distinguiu entre lei e Direito frente às posturas positivistas. ${ }^{17}$ E, identicamente, Benda proclama a excelência do princípio da dignidade humana na Constituição tedesca, ao ponderar que a norma do artigo $1.1 \mathrm{GG}$ além de projetar-se valorativamente sobre as normas reguladoras da relação do indivíduo com o Estado, na esfera dos direitos fundamentais, ainda "permeia profundamente tudo o que comporta o Estado livre e democrático de Direito. (...) Sempre se terá de ter em conta esse artigo 1.1 como parâmetro valorativo na especial interpretação desses direitos fundamentais". ${ }^{18}$

Quanto ao fecundo labor interpretativo e afirmativo do princípio da dignidade humana, desenvolvido pela Corte Constitucional tedesca, não escapa a Perez a precisa observação de que ele figura entre os princípios básicos da Constituição, que dominam todos os preceitos da Lei fundamental. Refere, ademais, a afirmação de alguns autores de que ele contém o princípio supremo da Constituição, surgindo ele continuamente nas sentenças do Tribunal Constitucional Federal em defesa da dignidade da pessoa, independentemente da idade e da capacidade mental. "Onde existe vida humana, há de reconhecer-se-lhe a dignidade correspondente, sem que seja

15 SILVA, José Afonso da. A dignidade da pessoa humana como valor supremo da democracia. Revista de Direito Administrativo. Rio de Janeiro, v.212, abril/junho de 1998, p.89.

16 HESSE, Konrad. Manual de derecho constitucional. Madrid: Marcial Pons, 1996, p. 86. "A experiência de um regime totalitário que desprezou o ser humano e sua liberdade e o fato de que a carência de tradição não permitia considerar humanidade e liberdade como óbvias bases naturais do Estado, conduziram, após 1945, ao esforço por estabelecêlas e fortalecê-las no novo ordenamento até o maior grau possível de garantia. Desta forma, o novo ordenamento jurídico se baseia, já desde o art. $1 \mathrm{GG}$, no princípio supremo, absoluto e intangível, da inviolabilidade da dignidade humana (art. 1.1 GG) e no reconhecimento dos direitos invioláveis e inalienáveis do homem (art. 1.2 GG)."

17 VERDÚ, Pablo Lucas. Teoria de la constitución como ciencia cultural. Madrid: Dyckinson, 1997, p.33.

18 BENDA, Ernst. Dignidad humana y derechos de la personalidad. In: BENDA, Ernst et alii. Manual de derecho constitucional. Madrid: Marcial Pons, 1996, p.121. 
decisivo que o sujeito esteja consciente desta dignidade e saiba guardá-la por si mesmo." 19

A Benda cabe, ainda, a relevante afirmação de que a Lei Fundamental de Bonn é um ordenamento constitucional comprometido com valores. Como tal, "reconhece a proteção da liberdade e da dignidade humana como fim supremo de todo o Direito (breve 12, 45 (51)). O art. 1 GG faz deste objetivo o supremo princípio constitutivo da Lei Fundamental". ${ }^{20}$ Com efeito, constituindo lógica decorrência, ao lado dos princípios da legalidade, divisão dos poderes, democracia representativa, forma republicana, federalismo e Estado social, a Lei Fundamental germânica, no artigo 79, III, institui como cláusula pétrea o princípio de inviolabilidade da dignidade humana contido no art. 1.1 daquela. Dessarte, no ordenamento constitucional germânico, a dignidade da pessoa humana é o fio condutor de toda a sua estruturação, com as necessárias decorrências infraconstitucionais.

\subsection{A Constituição de Portugal}

A Constituição de Portugal, promulgada em 1976, por razões históricas semelhantes às da Alemanha, diz José Afonso da Silva, igualmente dispôs, modo expresso, sobre a dignidade humana: Portugal é uma República soberana, baseada na dignidade da pessoa humana e na vontade popular e empenhada na construção de uma sociedade livre, justa e solidária. ${ }^{21}$ Neste ponto, o ordenamento português coincide com o alemão, porquanto também tem por base o princípio da dignidade da pessoa humana. Confirma-o a doutrina, com Vieira de Andrade. ${ }^{22}$ Com Moderne, a reafirmação. ${ }^{23}$

De Verdú, colhe-se a análise de que a Constituição lusitana reconhece e estabelece o valor inerente da dignidade

19 PÉREZ, Jesus Gonzalez. Op. cit., p.53.

20 BENDA, Ernst. Op. cit., p.118.

21 SILVA, José Afonso da. A dignidade da pessoa humana como valor supremo da democracia. Op. cit., p.89.

22 VIEIRA DE ANDRADE, José Carlos. Os direitos fundamentais na constituição portuguesa de 1976. Coimbra: Almedina, 1987, p.101 e 102. "Neste contexto se deve entender o princípio da dignidade da pessoa humana, afirmado logo no artigo $1^{\circ}$ da Constituição, como o princípio fundamental que está na base do estatuto jurídico dos indivíduos e confere unidade de sentido ao conjunto dos preceitos relativos aos direitos fundamentais. (...) Realmente, o princípio da dignidade da pessoa humana está na base de todos os direitos constitucionalmente consagrados, quer dos direitos e liberdades tradicionais, quer dos direitos dos trabalhadores e direitos a prestações sociais."

23 MODERNE, Franck. La dignité de la personne comme principe constitutionnel dans les constitutions portugaise et française. In: MIRANDA, Jorge (org.) Perspectivas 
humana, sendo esta a Grundnorm de um ordenamento fundamental conforme os valores. A interpretação dos direitos, liberdades e garantias do Título II, Capítulo I, do Texto Básico português "significa que tais direitos, liberdades e garantias formais são premissas concordantes da Constituição de modo que a Lei Maior portuguesa há de interpretarse à luz da dignidade humana". ${ }^{24}$

Cardoso da Costa, por sua vez, comenta que, além da referência emblemática que lhe faz no seu artigo $1^{\circ}$, a Constituição de Portugal não enuncia o princípio da dignidade da pessoa humana no seu catálogo de direitos fundamentais, pois é mais do que isso, já que "representa o "princípio de valor' que é o fundamento mesmo (e o 'critério') desses direitos e do respectivo catálogo - catálogo ao qual confere uma "unidade de sentido". ${ }^{25}$

\subsection{A Constituição da Espanha}

A vigente Constituição espanhola, promulgada após o crepúsculo do regime franquista, abre seu texto (art. $\left.1^{\circ}, 1\right)$ com a solene proclamação de que "A Espanha se constitui em um Estado social e democrático de Direito, que propugna como valores superiores de seu ordenamento jurídico a liberdade, a igualdade e o pluralismo político". ${ }^{26}$ Explicitando tais valores superiores, por sua vez, inseriu o princípio da dignidade da pessoa humana em seu artigo $10, \mathrm{n}^{\circ}$ 1, com a seguinte dicção: A dignidade da pessoa, os direitos invioláveis que lhe são inerentes, o livre desenvolvimento da personalidade, o respeito à lei e ao direito dos demais são fundamentos da ordem política e da paz social". ${ }^{27}$

constitucionais nos vinte anos da constituição de 1976. Coimbra: Coimbra Editora, 1996, vol. I, p. 205. "Se a dignidade da pessoa humana representa assim o primeiro fundamento da República, a base mesma 'dos direitos fundamentais e das liberdades essenciais' assim como 'a garantia de seu exercício e de seu uso’ (art. 2 da Constituição), ela irriga o grande leque de direitos reconhecidos pela Constituição portuguesa, ela 'dá um senso a todos os direitos fundamentais'. Tanto assim que, à diferença da maioria das outras constituições européias, a Constituição de 1976 dá lugar aos direitos fundamentais eventuais, que virão a se impor à consciência jurídica coletiva ou que se originarão 'das leis e das regras de direito internacional aplicáveis’ (art. 16-1 da Constituição): estes futuros direitos deverão ser conformes às exigências da dignidade humana, tal qual é proclamada pelo artigo primeiro da lei fundamental."

24 VERDÚ, Pablo Lucas. Op. cit., p.203.

25 CARDOSO DA COSTA, José Manuel Moreira. O princípio da dignidade da pessoa humana na constituição e na jurisprudência constitucional portuguesas. In: BARROS, Sérgio Resende de e ZILUETI, Fernando Aurélio (coord.). Direito constitucional - estudos em homenagem a Manoel Gonçalves Ferreira Filho. São Paulo: Dialética, 1999, p.192.

26 Tradução livre do espanhol pelo autor.

27 Livre tradução do espanhol pelo autor. 
De Peces-Barba a observação de que a Constituição espanhola é pioneira no emprego da expressão "valores superiores", porquanto pouco comum, no âmbito do direito comparado, o uso dessa terminologia, mesmo que se reconheça que "a jurisprudência da República Federal Alemã construa um sistema de valores, deduzindo-o do ordenamento constitucional". ${ }^{28}$

A expressão "valores superiores", segundo visão coincidente de vários autores espanhóis, alcança uma compreensão abrangente. Com efeito, "a dignidade da pessoa humana, no ordenamento jurídico espanhol, não só se constitui em um valor superior ela mesma (ainda que referida em artigo diverso do 1.1), como é o próprio fundamento ético, axiológico, a justificação, o valor que ocupa posição central e legitimadora, a norma fundamental e fundamentadora deste ordenamento", como anota Luíza Matte. ${ }^{29}$

A propósito, González Perez refere que a dignidade da pessoa constitui um dos valores superiores que o Direito positivo não pode ignorar, assim como não pode desconhecer os direitos à mesma inerentes. A Constituição contempla a dignidade da pessoa humana como um dos valores do ordenamento jurídico espanhol. Se fosse possível escalonar os valores em ordem de prioridade, ocuparia o primeiro lugar a dignidade da pessoa humana. "Desde o ponto de vista axiológico, a dignidade da pessoa 'é o fundamento, princípio e origem do ordenamento constitucional espanhol, é a Grundnorm em sentido lógico, ontológico e deontológico"". ${ }^{30}$ Na mesma linha de González Perez, pronuncia-se Díaz Revorio. ${ }^{31}$

28 PECES-BARBA Martínez, Gregorio. Temas clave de la constitución española - los valores superiores. Madrid: Tecnos, 1986, p.49.

29 MATTE, Luíza. A dignidade da pessoa humana em abstrato, sua positivação e sua influência na prática jurídica. Porto Alegre: PUCRS: 2000. 183 p. Dissertação (Mestrado em Direito) - Faculdade de Direito, Pontifícia Universidade Católica do Rio Grande do Sul, 2000, p.69.

30 GONZÁLEZ PÉREZ, Jesús. Op. cit., p.82 e 83.

31 DÍAZ REVORIO, Francisco Javier. Valores superiores e interpretación constitucional. Madrid: Centro de Estudios Políticos y Constitucionales, 1997, p. 117 e 118. "Em nossa opinião, a referência ao 'fundamento da ordem política e da paz social' ressalta o caráter essencial da dignidade e dos demais conceitos do artigo 10.1 para o Estado e para a sociedade; ademais, ainda que a referência ao Ordenamento jurídico não seja explícita como no artigo 1.1, também pode considerar-se que ditos elementos são fundamento de dito ordenamento. (...) Destacou-se que a dignidade preside o preceito e ocupa uma posição central dentro do mesmo. Os restantes conceitos que menciona dito artigo, ainda que possam ser considerados valores, não seriam superiores, já que a maioria deles pode ficar englobada na própria dignidade ou em algum dos restantes valores superiores: assim acontece com 'os direitos invioláveis', conseqüência da dignidade da pessoa, ou o livre desenvolvimento da personalidade, que é uma manifestação do valor liberdade e da própria dignidade." 
Corroborando os precedentes autores, afirma Peces-Barba que o fundamento destes valores superiores do art. 1.1 é um fundamento racional e histórico que representa o juízo do legislador constituinte, ratificado em referendum, e que se converte, por esse modo, em um grande acordo social, caracterizador de um consenso básico de que estes valores superiores e sua inserção profunda são o fundamento para a realização dos objetivos básicos do Estado, quais sejam, o desenvolvimento da dignidade humana através da vida social, tornando possível a plenitude desta dignidade. "O acordo não é, pois, arbitrário, senão que recolhe uma moralidade baseada na dignidade humana, e com a pretensão de que a organização da vida social favoreça, aprofunde e desenvolva essa dignidade humana." ${ }^{\prime 2}$

\subsection{A Constituição da República Italiana}

Promulgada no imediato pós-guerra (27 de dezembro de 1947), a Constituição da República da Itália, dispensado o clássico preâmbulo, no título de abertura, contempla os princípios fundamentais, "os quais proporcionam os traços essenciais do rosto do Estado e representam o fundamento ideológico do ordenamento estatal". ${ }^{33}$ Embora sem a forma direta e literal de afirmação da dignidade da pessoa humana como princípio fundamental do ordenamento jurídico itálico, dita Constituição a contempla já em seu artigo $2^{\circ}$ : La Repubblica riconosce e garantisce $i$ diritti inviolabili dell'uomo, sia come singolo sia nelle formazioni sociali ove si svolge la sua personalità, e richiede l'adempimento dei doveri inderogabili di solidarietà politica, economica e sociale. ${ }^{34}$

Reitera o princípio no art. $3^{\circ}$, in verbis:

Tutti i cittadini hanno pari dignità sociale e sono eguali davanti alla legge, senza distinzione di sesso, di razza, di lingua, di religione, di opinioni politiche, di condizioni personali e sociali.

È compito della Repubblica rimuovere gli ostacoli di ordine economico e sociale, che, limitando di fatto la libertà e l'eguaglianza dei cittadini, impediscono il pieno sviluppo della

32 PECES-BARBA Martínez, Gregorio. Op. cit., p.43 e 112.

33 ITÁLIA. Presidência do conselho de ministros, serviços de informações e da propriedade literária, El Estado italiano y su ordenamiento, p.3.

34 Em livre tradução, pelo autor, o texto expressa: “A República reconhece e garante os direitos invioláveis do homem, seja como indivíduo ou nos agrupamentos sociais onde desenvolve sua personalidade, e exige o cumprimento dos inderrogáveis deveres de solidariedade política, econômica e social". 
persona humana e l'effettiva partecipazione de tutti i lavoratori all'organizzazione politica, economica e sociale del Paese. ${ }^{35}$

Sem dúvida, albergou, nas disposições citadas, o princípio da dignidade da pessoa humana, com o correlativo da isonomia, ainda que sem a desenvoltura das disposições literais das outras Constituições vistas. Com efeito, o desenvolvimento da personalidade ganha reiterada e expressa proteção. Dessarte, Ambrosini, em comento à Consituição da Itália, expressa-se, ao analisar os princípios fundamentais, afirmativamente quanto a ter o texto constitucional atribuído à tutela da pessoa humana uma relevância de princípio cardeal, e de ter a pessoa humana merecido uma consideração privilegiada, assim no aspecto físico como no moral. ${ }^{36}$
Sintonizado com Ambrosini, refere Zagrebelsky que a Itália aderiu às convenções internacionais de direitos do homem, fundadas na dignidade da pessoa humana, destacando, ainda, o papel que desempenham os artigos supracitados na jurisprudência dos tribunais superiores. Com efeito, lembra ele que "o Tribunal de Cassação, em sua atividade de interpretação global do sistema jurídico, precedeu ao Tribunal Constitucional ao afirmar a existência de um direito à livre manifestação da personalidade, segundo o artigo 2 da Constituição". ${ }^{37}$ Prossegue, ponderando que o Tribunal Constitucional italiano tem "decisões que reconhecem o valor da pessoa humana" (11/1956) e proclamam a existência de "bens fundamentais que formam parte do patrimônio inviolável da pessoa humana (33/1974) $)^{\text {38 }}$, fechando a análise com

35 A disposição constitucional, em livre tradução pelo autor, proclama que "Todos os cidadãos têm igual dignidade social e são iguais perante a lei, sem distinção de sexo, raça, língua, religião, opiniões políticas e de condições pessoais e sociais. É incumbência da República remover os obstáculos de ordem econômica e social, que, limitando de fato a liberdade e a igualdade dos cidadãos, impedem o pleno desenvolvimento da personalidade humana e a efetiva participação de todos os trabalhadores na organização política, econômica e social do País".

36 AMBROSINI, Giangiulio. Costituzione italiana. Torino: Piccola Biblioteca Eunaudi, 1975, p.26. O texto, livremente traduzido e sumariado pelo autor, é este: Repubblica, democrazia, egualglianza dei cittadini, sono sicuramente principi cardine dell'ordinamento, e sulla loro essenzialità non vi può essere problema. Per quanto caratterizzanti, essi non esauriscono la gamma dei principi fondamentali accolti dalla Costituzione. A bem guardare nel texto costituzionale, una rilevanza non dissimile deve essere attribuita alla tutela della persnoa humana... La persona humana há una considerazione privilegiata, sia sotto il profilo fisico (libertà personale), sia sotto il profilo morale.

37 ZAGREBELSKY, Gustavo. El tribunal constitucional italiano. In: FAVOREU, L. et alii. Tribunales constitucionales europeos y derechos fundamentales. Madrid: Centro de estudios constitucionales, 1984, p.423.

38 ZAGREBELSKY, Gustavo. Op. cit., p.422. 
esta idéia: "Em suma, a proclamação de direitos fundamentais possui uma força expansiva no sistema jurídico e exige uma verdadeira 'política de direitos fundamentais'. Isto se vê reforçado pelo artigo $3 " .{ }^{39}$

Essa força expansiva do princípio constitucional da dignidade da pessoa humana merece de Palazzo, ao estudar os valores constitucionais incidentes no Direito Penal, a afirmação de que, contraposta à intrínseca politicidade do direito penal, existe uma constante exigência de eticidade, própria do direito penal. Com eticidade se pode “'simplesmente' aludir ao fato de que se, no manancial do direito penal, se encontram a política e a exigência da tutela da sociedade, em seu âmago se encontra a pessoa humana". ${ }^{40}$

\section{A POSITIVAÇÃO DO PRINCÍPIO NA CONSTITUIÇÃO DO BRASIL}

Por derradeiro, a Constituição da República do Brasil. Com efeito, a tortura e outras formas de desrespeito à pessoa humana, praticados durante $o$ regime militar, pondera José Afonso da Silva, ${ }^{41}$ deram ao Constituinte brasileiro de 1988 a motivação e justificativa para inserir a dignidade da pessoa humana como um dos fundamentos do Estado
Democrático de Direito da República Federativa do Brasil, ao dispor, no artigo $1^{\circ}$, inc. III, da CR: A República Federativa do Brasil, formada pela união indissolúvel dos Estados e Municípios e do Distrito Federal, constitui-se em Estado Democrático de Direito e tem como fundamentos: III - a dignidade da pessoa humana.

O estudo deste último tópico cingese ao escopo demonstrativo do forte elo existente, no pertinente, entre o ordenamento brasileiro e os ordenamentos constitucionais europeus referidos, tomados como modelo. Convém notar, com efeito, que o Brasil adota, quanto à constitucionalização do princípio da dignidade da pessoa humana, a concepção denominada de personalismo humanista, característica do constitucionalismo de valores que caracteriza a própria cultura ocidental dos nossos dias.

\section{A DIGNIDADE DA PESSOA HUMANA COMO FUNDAMENTO DO ESTADO}

Neste segmento da dissertação, presente seu objeto específico, intentase verificar a presença da dignidade da pessoa humana na tessitura constitucional brasileira, na qualidade e função de princípio fundante de tal ordem constitucional. De tal escopo decorre

39 Ibidem, p.436.

40 PALAZZO, Francesco C. Valores constitucionais e direito penal. Tradução de Gérson Pereira dos Santos. Porto Alegre: Sergio Antônio Fabris, 1989, p.17.

41 SILVA, José Afonso da. A dignidade da pessoa humana como valor supremo... Op. cit., p.89. 
a busca de um real significado e respectiva eficácia para o princípio.

A República Federativa do Brasil constitui-se em Estado Democrático de Direito, na precisa prescrição do art. $1^{\circ}$ da Lei Magna. Na democracia, o Estado não é fim mas meio, concebido como instrumento a serviço do ser humano. Este, na precisa ponderação de Souza Junior, ${ }^{42}$ como Pessoa Humana, é anterior e superior ao próprio Estado. Com efeito, a concepção de que o homem é uma Pessoa, isto é, um ser, a um tempo, individual e social, material mas espiritualmente aberto ao transcendente, e, de conseqüência, dotado de dignidade e de direitos fundamentais a serem preservados e promovidos pelo Estado, foi o princípio a partir do qual plasmou-se, na Europa, a denominada civilização cristã ocidental. Foi no âmbito dessa nova civilização que se consolidou a idéia do Estado a serviço da dignidade e dos direitos da pessoa. É pois, a idéia do Estado democrático.

A vigente Constituição da República, ao dispor o princípio em tela, fê-lo sob motivações várias, dentre as quais a de exorcizar o período autoritário antecedente à sua edição, porquanto violador de direitos fundamentais e, por isso, desrespeitador da dignidade da pessoa humana, na condução dos negócios de Estado. Quanto à linha principiológica seguida, buscou inspiração nas congêneres da Alemanha, Itália, Portugal e Espanha, tornando expresso o compromisso jurídico com a dignidade da pessoa humana. A propósito do pioneirismo interno daí decorrente, destaca Sarlet que a atual Constituição da República foi a primeira, no constitucionalismo brasileiro, a instituir um título próprio para os princípios fundamentais, "situado, em manifesta homenagem ao especial significado e função destes, na parte inaugural do texto, logo após o preâmbulo e antes dos direitos fundamentais". ${ }^{43}$

De notar, igualmente, que, na história do constitucionalismo pátrio, é a primeira vez que aparece positivado o princípio da dignidade da pessoa humana como fundamento do Estado Democrático de Direito. O que ocorre no artigo $1^{\circ}$., inciso III, da CRFB: A República Federativa do Brasil, formada pela união indissolúvel dos Estados e Municípios e do Distrito Federal, constitui-se em Estado Democrático de Direito e tem como fundamentos: III - a dignidade da pessoa humana. Compreender, pois, a dignidade da pessoa como princípio constitucional é traçar-lhe o alcance estruturante e surpreender-lhe a eficá-

42 SOUZA JUNIOR, Cezar Saldanha. A crise na democracia no Brasil. Rio de Janeiro: Forense, 1978, p.3 e 4.

43 SARLET, Ingo Wolfgang. Dignidade da pessoa humana e direitos fundamentais na Constituição Federal de 1988. Porto Alegre: Livraria do Advogado, 2001, p.61. 
cia sistêmica no plano das conseqüências jurídicas, destas possibilitando destacar, exemplificativamente algumas, como adiante se verá.

É ainda Sarlet a constatar que o legislador constitucional, via instituição de princípios fundamentais em título próprio, deixou clara a sua intenção de outorgar aos princípios fundamentais a textura de "normas embasadoras e informativas de toda a ordem constitucional, inclusive dos direitos fundamentais, que também integram aquilo que se pode denominar de núcleo essencial da Constituição material". ${ }^{44}$ E tal é o relevo dado pelo legislador constituinte ao princípio da dignidade da pessoa humana que aparece ele expresso em várias outras disposições da arquitetura constitucional. Assim no artigo 170, caput, dispondo que "A ordem econômica, fundada na valorização do trabalho humano e na livre iniciativa, tem por fim assegurar a todos existência digna, conforme os ditames da justiça social..." De igual modo, no título da ordem social capítulo relativo à família, criança, adolescente e idoso - previu (artigo 226, parágrafo $6^{\circ}$ ) o planejamento familiar fundado nos princípios da dignidade da pessoa humana e da paternidade responsável, assegurando o direito à dignidade à criança e ao adolescente (artigo 227, caput).
Logo, a dignidade da pessoa humana, conquanto tardiamente reconhecida no plano normativo, está induvidosamente positivada na ordem constitucional pátria. Constitui, sem dúvida, princípio normativo fundamental, com a qualificação de norma jurídica fundamental da ordem jurídica. ${ }^{45} \mathrm{Com}$ isto, de logo, toma-se posição quanto à natureza jurídica do princípio, pois, em sendo dado com caráter normativo, resta dar-lhe classificação como espécie, ao lado das regras, no âmbito genérico das normas.

\section{O PRINCÍPIO DA DIGNIDADE DA PESSOA HUMANA COMO VALOR FUNDAMENTAL}

\subsection{Notas preliminares}

Resulta, do exposto no capítulo precedente, que os princípios gerais de direito, de fonte subsidiária nos Códigos, passaram, com as Constituições da segunda metade do século XX, a constituir fonte primária de normatividade, dando corpo, na ordem jurídica, aos valores supremos desta, dos quais derivam os direitos e as garantias fundamentais. Desta forma, como sintetiza Bonavides, os princípios, enquanto valores, constituem o critério de aferição dos conteúdos constitucio-

44 SARLET, Ingo Wolfgang. A eficácia dos direitos fundamentais. 2.ed. Porto Alegre: Livraria do Advogado, 2001, p.101.

45 SARLET, Ingo Wolfgang. Dignidade da pessoa humana e direitos... p.66. 
nais em sua dimensão normativa maior. ${ }^{46}$ Como já destacado, a dignidade da pessoa humana foi erigida, pelo legislador constituinte, a fundamento, embora não único, do Estado Democrático de Direito da República Federativa do Brasil (art. $1^{\circ}$, III), pelo que o Parlamento pátrio tomou uma decisão política fundamental relativamente ao sentido, à finalidade e à justificação do exercício do poder estatal e do próprio Estado. ${ }^{47}$

Ao inserir tal princípio na tessitura constitucional, definiu, de forma categórica, a relação homem-Estado: este existe para aquele, sendo o Estado instrumento a serviço da pessoa humana. Esta é a razão de ser do Estado e não meio para que o Estado alcance fins. ${ }^{48}$ Aceita esta premissa, evidente resta a adoção de princípios-valores no arcabouço constitucional brasileiro, com destaque para o da dignidade da pessoa humana na precípua função de norma fundamental do ordenamento. Com efeito, o Constituinte de 1988, coerentemente com esta opção (decisão política) fundamental, não incluiu a dignidade da pessoa humana no elenco dos direitos e garantias fundamentais, porquanto estes concretizam derivação lógica daquele. Não quer isto significar, é bem de ver, que, ao positivar constitucionalmente a dignidade da pessoa humana como princípio fundante da ordem jurídica, tenha o Constituinte pretendido aprisionar aquela ao âmbito da ordem jurídica, porquanto a dignidade humana tem existência independente da positivação e do grau deste reconhecimento legal, como valor imanente que é. Porém, do nível do reconhecimento e positivação do princípio da dignidade da pessoa pela ordem constitucional dependerá a efetividade deste. ${ }^{49}$

\subsection{O princípio da dignidade humana como norma suprema}

Os princípios, positivados constitucionalmente, constituem as normas supremas do ordenamento jurídico, ou seja, a norma das normas. Este processo se opera quando, segundo Gordillo Cañas, a Constituição materializa uma ordem objetiva de valores, o que se dá quando a dignidade da pessoa humana e os direitos da personalidade constituem os esteios da ordem política e social. ${ }^{50}$ Neste contexto, pois, o princípio da dignidade da pessoa humana exsurge como supremo valor da ordem constitucional, presente a

46 BONAVIDES, Paulo. Curso de Direito Constitucional. 10.ed. São Paulo: Malheiros, 2000, p. 254 .

47 SARLET, Ingo Wolfgang. Dignidade da pessoa humana e direitos ... p.66.

48 BLECKMANN, A. Apud SARLET, Ingo Wolfgang. Dignidade da pessoa humana e direitos ... p.66.

49 SARLET, Ingo Wolfgang. Dignidade da pessoa humana e direitos ... p.69.

50 ApudBONAVIDES, Paulo. Op. cit., p.260-1. 
moderna visão da doutrina constitucional que compreende a Lei das Leis como expressão do "consenso social sobre os valores básicos". ${ }^{51}$ Em sendo valor fundamental da ordem constitucional, o princípio da dignidade da pessoa humana (art. $1^{\circ}$, III) projeta uma eficácia de valor unificador dos direitos fundamentais, sendo-lhe fonte jurídicopositiva. ${ }^{52} \mathrm{O}$ princípio é, pois, o valor que dá unidade e coerência aos direitos fundamentais em seu conjunto, independentemente de estarem rotulados como tal e elencados no artigo $5^{\circ}$ (direitos e deveres individuais e coletivos), nos artigos $6^{\circ}$ a 11 (direitos sociais) ou nos artigos 14 a 17 (direitos políticos).

Sobreleva notar, como faz Sarlet, que a dignidade da pessoa humana, como valor intrínseco desta, elevada a princípio constitucional fundamental, não é passível de ser concedida pelo ordenamento jurídico, porquanto o precede e fundamenta.

Neste sentido, vista a contrário senso, decisão do Tribunal Federal Constitucional da Alemanha estabelecendo que nenhuma pessoa humana poderá ser privada da respectiva dignidade, conquanto possa ser violada a pretensão de respeito e proteção que dela decorre..$^{53}$ Logo, a dignidade da pessoa humana, por inerência humana e princípio-valor fundamentador da ordem jurídica, não constitui e nem poderá ser um direito fundamental a ser concedido.

Decorre, pois, que o princípio da dignidade da pessoa humana, tanto quanto na Alemanha, é valor superior que precede a e está materializado na ordem constitucional vigente no Brasil.

Sendo, aliás, notória e, de todo modo, amplamente referida na parte primeira deste trabalho, a inspiração haurida pelo Constituinte brasileiro do pensamento constitucional europeu, nomeadamente Alemanha, Espanha, Portugal e Itália, dúvidas não restam de que a Constituição da República Federativa do Brasil foi erigida como sistema de valores, à semelhança daquelas que a influenciaram decisivamente.

A propósito, segundo Francisco Fernandez Segado, referido por Fernando Ferreira dos Santos, ${ }^{54}$ há unanimidade entre os constitucionalistas espanhóis no sentido de que a ordem constitucional de Espanha constitui um sistema de valores. Com isto, na ponderação do citado autor, a Lei Maior espanhola de 1978 teve por escopo transpor o reducionismo do positivismo estatal, consagrando a dimensão axiológica do Direito, de modo que o

51 BONAVIDES, Paulo. Op. cit., p.261.

52 FARIAS, Edilsom Pereira de. Colisão de direitos. Porto Alegre: Sergio Antonio Fabris, 1996, p.54.

53 SARLET, Ingo W. Op. cit., p.71.

54 FERREIRA DOS SANTOS, Fernando. Princípio constitucional da dignidade da pessoa humana. São Paulo: Celso Bastos, 1999, p.57-8. 
ordenamento jurídico estatal não haure legitimidade de si mesmo, por proceder do Estado, em conformidade com os procedimentos formais de produção das normas jurídicas, como apregoava Hans Kelsen. Nem é um sistema axiologicamente neutro, que pode orientarse a qualquer fim, com todos os perigos que disso decorre, como a história recente dá conta. Contrariamente a esta superada concepção positivista, o Direito, consubstanciado na ordem jurídica, constitui um instrumento para a realização dos fins que a Constituição enuncia como valores.

Uma vez aceito que a qualificação da dignidade da pessoa humana como princípio constitucional fundamental (art. $1^{\circ}$, III, CRFB) constitui, não mera declaração de conteúdo ético, mas norma jurídica positivada, de natureza constitucional formal e material, dotada de plena e pronta eficácia, há de se admitir, com Benda ${ }^{55}$, que ela alcança a condição de valor jurídico fundamental da comunidade. Nessa linha argumentativa, pondera, ainda, Sarlet ${ }^{56}$, com apoio em doutrina de K. Stern, que, como princípio fundamental, a dignidade da pessoa humana é valor-guia dos direitos fundamentais e assim de toda a ordem jurídica (constitucional e infraconstitucional), "razão pela qual, para muitos, se justifica plenamente sua caracterização como princípio constitucional de maior hieraquia axiológico-valorativa".

\subsection{O princípio da dignidade humana como norma e valor fundamentais}

Até aqui, trabalhou-se, como o fazem os autores em sua maioria, na perspectiva identificadora de princípio e valor, à medida em que aquele, como espécie de norma, é sempre portador ou expressão deste. Passando ao largo da conhecida e diferenciadora posição teórica de Robert Alexy ${ }^{57}$, e para além

55 Cf. E. Benda, apud Ingo W. Sarlet. A dignidade da pessoa humana e os direitos fundamentais... p.71-2.

56 SARLET, Ingo W. Op. cit., p.72.

57 O jusfilósofo alemão, em sua Teoria dos Direitos Fundamentais, trata princípios e valores como categorias lógicas distintas. Como pontos de identificação, aduz que se pode cogitar de uma colisão e respectiva ponderação de princípios e assim também, de uma colisão e respectiva ponderação de valores. Igualmente, a possibilidade de realização gradual dos princípios admite a contrapartida da realização também gradual dos valores. Em decorrência, a Corte Constitucional alemã elabora enunciados sobre princípios aplicáveis a valores e vice-versa, mantendo-se válido o conteúdo deles. Mas, para além das semelhanças, refere haver uma especial diferença entre princípios e valores. Com efeito, enquanto os princípios são conceitos de tipo deontológico (consistente num mandado ou dever ser), os valores são conceitos do tipo axiológico, que se expressam pela idéia de que algo é bom e não de algo é devido. 
dela, intenta-se colher uma precisa idéia de valor, aplicável ao presente ensaio. Com a brevidade que a natureza do presente trabalho requer, parte-se da premissa de que o princípio, antes de específico mandado de otimização da concepção alexeniana, é norma de conduta, porquanto, positivado, impõe um agir de certo modo, constituindo medida ou referência de comportamento, com as características próprias da espécie, consistentes na generalidade, obrigatoriedade e coercitividade. Assim, sendo a Constituição a primeira das normas, e presente a tendência atual da constitucionalização de valores, como antes visto, com destaque para a dignidade da pessoa humana, elevada a princípio e valor supremos, tem-se que é central o conceito de valor nessa construção.

Com efeito, na compreensão de autores vários, valor identifica-se com o fim do ser. Fim este que é ontológico por tomar parte do próprio ser, no caso, o humano. Tal é o conceito colhido de Armando Câmara, para quem "valor é a relação de conformidade do dinamismo do ser com seus fins". ${ }^{58}$ Dito noutros termos, mas na mesma perspectiva, "O valor é o próprio ser, visionado racionalmente, numa perspectiva teleológica, em livre posicionamento de conformidade dos seus dinamismos com seus fins". ${ }^{59}$ Por seu turno, os fins do ser humano são alcançáveis por um meio não ontológico, que é a razão. Esta age na perspectiva axiológica, fazendo com que o fim do ser humano seja concebido como um bem. Os valores, pois, são fins do ser. ${ }^{60}$ Voltando a Armando Câmara, temse que a percepção do valor na mente humana surge quando a razão, descobrindo os fins do ser humano, para os quais se projeta todo o dinamismo do ser, percebe a conformidade desses dinamismos finalizados com os próprios fins, que levam à realização total e plena do ser humano. ${ }^{61}$

Diaz Revorio ${ }^{62}$, em comento à Constituição espanhola, na perspectiva do sistema de valores por ela consagrados, manifesta-se no sentido de que lhe parece adequado correlacionar os valores com o finalístico bem, porquanto este constitui um critério ao qual correspondem os valores explicitados normativamente na Constituição. Assim sendo, o bem materializa-se como o devido. De notar-se, porém,

58 DE BONI, Luiz Alberto (org.). Armando Câmara. Porto Alegre: EDIPUCRS, 1999, Coleção Pensadores gaúchos, p.134 e 135.

59 Ibidem, p. 54 e 55.

60 ARAGÓN REYES, Manuel. Constitución y democracia. Madrid: Tecnos, 1989, p. 85. 61 Cf. Armando CÂMARA in Jacy de Souza MENDONÇA, Diálogos no solar dos Câmara, Porto Alegre: EDIPUCRS, 1999, Coleção Pensadores gaúchos, p.134.

62 DÍAZ REVORIO, Francisco Javier. Op. cit., p.95 e 107. 
que valor é um conceito que, além de jurídico, é metajurídico, porquanto os valores, embora a ele pertençam, não se cingem ao mundo jurídico.

Identificando o valor com o fim do ser, tem-se a ponderação de Basave del Valle, para quem o ponto nuclear do valor está em sua ordenação teleológica, presente em sua própria natureza. Assim, o valor está na estrutura ôntica do ser humano, com suporte no mundo real, consistindo em uma manifestação ativa do ser, que está ordenado a um fim. ${ }^{63}$ Esta ordem de raciocínios onto-axiológicos torna plenamente pertinente a reflexão de Verdú quando pondera que a taxativa disjunção ser/valor, isto é, entre ontologia e axiologia, levaria à dessubstancialização dos valores. Assim, a perda da visualização metafísica dos valores conduz a um nominalismo axiológico contra o qual tanto se bateu Scheler. Tampouco consiste em substituir a ontologia pela axiologia, nem a essência pela existência. Pondera ele que, nesta rota de evolução, e "já no campo do direito constitucional, se chegaria à dessubstancialização da Constituição, dos valores superiores que propugna, da dignidade da pessoa, do conteúdo essencial dos direitos fundamentais e da distinção entre lei e Direito." ${ }^{44}$

Não é demasia ponderar que o processo de juridicização de um valor consiste na sua positivação e respectiva integração ao conteúdo da justiça. Em suma, os fins do ser, quando positivados em uma norma, constituem valores jurídicos. A propósito, Luíza Matte, ${ }^{65}$ com toda pertinência, refere ensinamento do Prof. Cezar Saldanha de Souza Junior, para quem as normas jurídicas podem ordenar condutas direta ou indiretamente a fins. Aquela norma que ordena condutas diretamente a fins tem por conteúdo material um valor, constituindo um princípio. Logo, princípio é espécie de norma e, como norma, baliza condutas, expressando um fim ou estando diretamente a serviço de um fim. De conseqüência e em suma, os princípios, em sendo normas, como as regras, são meios de atingir os fins a que o direito se propõe. Por sua vez, o direito, ele próprio, é essencialmente meio em relação à pessoa humana, na perspectiva de realização dos fins desta, que são ontológicos.

Do exposto, conclui-se que a dignidade da pessoa humana é valor jurídico e, como tal, conteúdo material do respectivo princípio. Com efeito, a

63 DEL VALLE, Basave. Filosofia do homem. Tradução de Hugo di Primio Paz. São Paulo: Convívio, 1975, p.161.

64 VERDÚ, Pablo Lucas, op. cit., p.115.

65 Op. cit., p. 95 . 
positivação constitucional da dignidade da pessoa humana, no art. $1^{\circ}$, inc. III, da Constituição da República, torna induvidosa sua condição de valor jurídico, com força normativa fundante da República Federativa do Brasil, constituída em Estado Democrático de Direito, sedimentando a premissa de que a pessoa humana é o fim primeiro e último, alfa e ômega, do direito e do Estado. Como valor superior e fundante da ordem constitucional, a dignidade da pessoa humana.

\section{CONCLUSÕES}

a) Hodiernamente, os ordenamentos jurídicos tendem ao reconhecimento da pessoa humana como o centro e o fim do Direito.

b) A pessoa humana é o fundamento primeiro do direito. Com efeito, o homem é o ser que, dentro do tempo e do espaço, se apresenta e deve ser considerado como 'centro e fim' de tudo o que existe, pois ele é pessoa, isto é, o ser em consciência e em liberdade.

c) A identidade do homem como pessoa o torna o valor absoluto - o único valor absoluto - a que tudo se refere. Este primado do homem não pode não ser reconhecido, acolhido, respeitado, promovido e tutelado

d) $\mathrm{O}$ direito tem um finalismo próprio que lhe legitima a presença na vida humana, consistente na busca do bem comum no qual se complementa o crescimento integral do homem. Tal finalismo jurídico se inscreve, obviamente, no finalismo da pessoa humana, porquanto esta é o fim último de tudo quanto existe no tempo e no espaço. ${ }^{66}$

e) Várias Constituições inspiraram a Constituição Brasileira na positivação do princípio da dignidade da pessoa humana, dentre as quais a Lei Fundamental da Alemanha, a Constituição de Portugal, a Constituição da República Italiana e a de Portugal.

f) A positivação do princípio vem expressa no artigo $1^{\circ}$, inc. III, da Constituição da República do Brasil: $A$ República Federativa do Brasil, formada pela união indissolúvel dos Estados e Municípios e do Distrito Federal, constitui-se em Estado Democrático de Direito e tem como fundamentos: III - a dignidade da pessoa humana.

g) A dignidade da pessoa humana, enquanto princípio, foi positivada como um dos fundamentos do Estado Democrático de Direito da República Federativa do Brasil.

h) O princípio da dignidade da pessoa humana foi positivado como valor fundamental da ordem jurídica brasileira.

i) O princípio da dignidade humana foi positivado como norma e valor fundamentais identificados, porquanto a dignidade da pessoa humana é valor jurídico e, como tal, conteúdo material do respectivo princípio. 


\section{REFERÊNCIAS}

ADORNO, Theodor W. Dialética Negativa, p. 330, apud GALEAZZI, Umberto. Por uma libertação da prisão da imanência. In: Deus na filosofia do Século XX. São Paulo: Loyola, 1998, p.359.

AMBROSINI, Giangiulio. Costituzione italiana. Torino: Piccola Biblioteca Eunaudi, 1975, p.26.

ARAGÓN REYES, Manuel. Constitución $y$ democracia. Madrid: Tecnos, 1989, p.85.

BLECKMANN, A. Apud SARLET, Ingo Wolfgang. Dignidade da pessoa humana e direitos ... p.66.

BONAVIDES, Paulo. Curso de Direito Constitucional. 10.ed. São Paulo: Malheiros, 2000, p.254.

CÂMARA, Armando, in MENDONÇA, Jacy de Souza. Diálogos no solar dos Câmara, Porto Alegre: EDIPUCRS, 1999, Coleção Pensadores gaúchos, p.134.

CANOTILHO, José Joaquim Gomes et MOREIRA, Vital. Constituição da República Portuguesa Anotada. 2.ed. Coimbra: Coimbra ed., 1984, v.1, p.70.

CARDOSO DA COSTA, José Manuel Moreira. O princípio da dignidade da pessoa humana na constituição e na jurisprudência constitucional portuguesas. In: BARROS, Sérgio Resende de e ZILUETI, Fernando Aurélio (coord.). Direito constitucional - estudos em homenagem a Manoel Gonçalves Ferreira Filho. São Paulo: Dialética, 1999, p.192.

DE BONI, Luiz Alberto (org.). Armando Câmara. Porto Alegre: EDIPUCRS, 1999, Coleção Pensadores gaúchos, p.134 e 135 .
DEL VALLE, Basave. Filosofia do homem. Tradução de Hugo di Primio Paz. São Paulo: Convívio, 1975, p.161.

DÍAZ REVORIO, Francisco Javier. Valores superiores e interpretación constitucional. Madrid: Centro de Estudios Políticos y Constitucionales, 1997, p.117 e 118.

FARIAS, Edilsom Pereira de. Colisão de direitos. Porto Alegre: Sergio Antonio Fabris, 1996, p. 54.

FERREIRA DOS SANTOS, Fernando. Princípio constitucional da dignidade da pessoa humana. São Paulo: Celso Bastos, 1999, p.57-8.

HESSE, Konrad. Manual de derecho constitucional. Madrid: Marcial Pons, 1996, p.86.

ITÁlIA. Presidência do conselho de ministros, serviços de informações e da propriedade literária, El Estado italiano y su ordenamiento, p.3.

LAFER, Celso. A reconstrução dos direitos humanos. São Paulo: Companhia das Letras, 1988, p.19.

MARTINI, Agostino. Il diritto nella realtà umana. Il diritto nel mistero della Chiesa Pontificium institutum utriusque juris - Pontificia Università Lateranense: Roma, 1986, p.6.

MATTE, Luíza. A dignidade da pessoa humana em abstrato, sua positivação e sua influência na prática jurídica. Porto Alegre: PUCRS: 2000. 183 p. Dissertação (Mestrado em Direito) Faculdade de Direito, Pontifícia Universidade Católica do Rio Grande do Sul, 2000, p.69.

MODERNE, Franck. La dignité de la personne comme principe constitutionnel dans les constitutions portugaise et française. In: 
MIRANDA, Jorge (org.) Perspectivas constitucionais nos vinte anos da constituição de 1976. Coimbra: Coimbra Editora, 1996, vol. I, p.205.

NOBRE JÚNIOR, Edilson Pereira. O direito brasileiro e o princípio da dignidade da pessoa humana. Revista de Direito Administrativo. Rio de Janeiro, v. 219, p. 237-251, janeiro/ março de 2000, p.238.

PALAZZO, Francesco C. Valores constitucionais e direito penal. Tradução de Gérson Pereira dos Santos. Porto Alegre: Sergio Antônio Fabris, 1989, p.17.

PECES-BARBA Martínez, Gregorio. Temas clave de la constitución española - los valores superiores. Madrid: Tecnos, 1986, p.49.

PEREZ, Jesus Gonzalez .La dignidad de la persona. Madrid: Civitas, 1986, p.19.

SARLET, Ingo Wolfgang. A eficácia dos direitos fundamentais. 2.ed. Porto Alegre: Livraria do Advogado, 2001.
SARLET, Ingo Wolfgang. Dignidade da pessoa humana e direitos fundamentais na Constituição Federal de 1988. Porto Alegre: Livraria do Advogado, 2001.

SILVA, José Afonso da. A dignidade da pessoa humana como valor supremo da democracia. Revista de Direito Administrativo. Rio de Janeiro, v. 212, abril/junho de 1998.

SOUZA JUNIOR, Cezar Saldanha. A crise na democracia no Brasil. Rio de Janeiro: Forense, 1978.

VIEIRA DE ANDRADE, José Carlos. Os direitos fundamentais na constituição portuguesa de 1976. Coimbra: Almedina, 1987, p.101 e 102.

ZAGREBELSKY, Gustavo. El tribunal constitucional italiano. In: FAVOREU, L. et alii. Tribunales constitucionales europeos y derechos fundamentales. Madrid: Centro de Estudios Constitucionales, 1984, p.423. 
